\title{
ARTE E PEDAGOGIA: ALÉM DOS TERRITÓRIOS DEMARCADOS
}

\author{
Ana Angélica Albano* \\ Não basta abrir a janela para ver os campos e o rio \\ Não é bastante não ser cego para ver as florestas, as árvores e as flores \\ É preciso também não ter filosofia nenhuma \\ Com filosofia não há árvores \\ Há ideias apenas \\ Há só cada um de nós como uma cave \\ Há só uma janela fechada \\ E todo mundo lá fora \\ E o sonho do que se poderia ver quando a janela se abrisse \\ Que nunca é o que se vê quando a janela se abre. \\ (Fernando Pessoa)
}

\begin{abstract}
RESUMO: O artigo apresenta uma experiência em projeto social com crianças em situação de risco social e pessoal, envolvendo uma pedagoga e um artista. Ambos estudavam na mesma universidade, mas só se encontravam no trabalho. Dividiam responsabilidades, mas não as partilhavam. Como professora de ambos, em disciplinas e institutos diferentes, tive a oportunidade de acompanhar de perto seus embates. Proponho, aqui, uma reflexão sobre a necessidade, apesar das dificuldades, de aproximação de profissionais dos campos da arte e da educação. E, também, sobre a importância de encontrarmos caminhos para a pesquisa em arte na educação, que respeitem a especificidade do campo. Tomando como referência a psicologia junguiana, procuro discutir a importância de encontrar na imagem o fio condutor para a pesquisa em arte e a necessidade de desenvolvermos uma observação atenta e cuidadosa durante a pesquisa, dando tempo para emergir tudo o que for necessário ser descoberto.

Palavras-chave: Arte. Educação. Psicologia junguiana. Pesquisa com imagens.
\end{abstract}

Doutora em Psicologia Social e professora da Faculdade de Educação da Universidade Estadual de Campinas (uniCAMP).E-mail: nanalbano@uol.com.br 
ART AND PEDAGOGY: BEYOND THE MARKED TERRITORIES

ABSTRACT: This paper presents an educational experience in a social project for children living in at-risk conditions, involving one pedagogue and one artist. Both of them were working on the same project and studying at the same university, but only met at the project site. They partook of the same responsibilities, but didn't share them with each other. As I taught both of these students, though they were in different institutes and teacher training courses, I could follow their debates very closely. My aim here is to reflect on the necessity, despite the difficulties, of bringing together professionals from the fields of art and education. I also focus on the importance of finding methodologies for art education research that respect the specificities of this field. Using Jungian psychology as my primary reference, I discuss the importance of using images as guidelines for research in art and the need to develop very attentive and respectful observation strategies, so that everything that needs to be discovered has time to emerge.

Key words: Art. Education. Jungian psychology. Research with images.

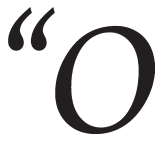

$s$ artistas são as minhas cruzes!". Desabafa, no primeiro dia de aula, a aluna de Pedagogia, referindo-se aos artistas com quem trabalhava em um projeto social, na periferia de Campinas.

A aula, em questão, é de uma disciplina da Faculdade de Educação da Universidade Estadual de Campinas (UNICAMP) - Educação, Corpo e Arte -, obrigatória para os alunos do curso de Pedagogia. É uma disciplina essencialmente prática, que não propõe um manual de atividades a serem repassadas na escola, mas cujo objetivo é promover vivências que possibilitem aos alunos reverem e ressignificarem sua relação com a arte e, posteriormente, refletirem por que e como incluí-la (ou não) no currículo. Meu desafio é levar os alunos a reconhecerem este lugar "sem lugar" da arte e, se possível, despertar neles o desejo de fruição e expressão através das linguagens artísticas.

Estamos ouvindo as experiências que aqueles estudantes têm ou tiveram com arte. Os relatos não variam muito: lembranças de desenhos para colorir na educação infantil, enfeites de festa junina, a participação em algum grupo de teatro ou de dança fora do currículo; com menos frequência, vêm à memória a visita a uma exposição, o envolvimento 
com um grupo musical ou o coro da igreja. Às vezes, alguém traz a lembrança de uma professora...

Apesar dos comentários pouco estimulantes, se questionados sobre a presença da arte na escola, invariavelmente, dizem que é importante porque desenvolve a criatividade e a sensibilidade. E param por aí. Mas, naquela aula, que começou como as outras, uma aluna, Caroline Silva, trazia uma experiência dissonante: os artistas são suas cruzes.

Seu desabafo levou-me a uma escola que atuei como professora, recém-saída da Faculdade de Artes Plásticas. Após o primeiro dia de aula, numa $5^{a}$ série do ensino fundamental, trabalhando numa sala projetada para aulas de arte, recebo da coordenadora pedagógica o seguinte comentário: "Quando a senhora for trabalhar com estes materiais rústicos (no caso, argila), a senhora poderia trabalhar no porão" (Albano Moreira, 2007). Ao que respondi com a coragem da inexperiência: "Mas todas as minhas aulas serão rústicas!”. Rústicas, leia-se, modelagem com argila.

Naquela ocasião, a minha cruz era a pedagoga, que não entendia as atividades de arte. Minhas lembranças aproximavam-me, portanto, daqueles artistas cruzes.

Logo mais, descobri que um dos artistas citados era Marcelo Polletto, aluno da licenciatura em Arte, que eu vinha acompanhando havia oito meses, no estágio supervisionado. Conhecia suas dificuldades, observava a angústia com que se debatia para encontrar uma via de comunicação com as crianças com quem trabalhava. Era um aluno extremamente falante, que tinha opinião para tudo, mas que estava mudo. Permanecia nas aulas em silêncio e para tudo que eu sugeria ele apenas retrucava: "mas é muito difícil na prática, mas é muito difícil, não, não dá!”.

Sempre havia ouvido com empatia as angústias daquele aluno, mas, naquele momento, precisava compreender porque ele era uma cruz para aquela pedagoga. E a resposta dela veio através de muitas perguntas:

Por que brigar tanto por uma sala boa, já que as crianças sempre sujam tudo? Por que insistem para que as crianças não desenhem com lápis antes de pintarem com tinta? Eles têm umas ideias que eu não entendo. As crianças pintam as paredes. Eles vivem dizendo para encontrar a própria 
voz, que voz é essa se estão dando aula de pintura? E eles sempre têm uma ideia na ponta da língua, um texto, um poema nas reuniōes... Para quê livros... se a aula é de pintura? Para quê música... se a aula é de pintura! Para quê o violão na sala? Por que chamavam a sala de ateliê? (Silva, 2003, p. 13)

Aquelas interrogações ficaram ressoando muito tempo em mim e acredito que o mesmo acontecia com Caroline, porque, meses mais tarde, me pediu que a orientasse no seu trabalho de conclusão de curso (TCC). Ela queria entender, finalmente, essa "tal de arte". E adotei o mesmo procedimento que adoto com todos os alunos da Pedagogia que me procuram para orientação: pedi que frequentasse minhas aulas de didática para o ensino de arte no curso de licenciatura em Artes Visuais. Havia constatado que, em geral, os alunos que buscam orientação vêm à procura de bibliografia e têm pouca ou nenhuma experiência artística. Sem a vivência no assunto, leem e repetem apenas o que já foi escrito e, assim, dificilmente acontece alguma transformação no modo de ver e compreender o problema que se propuseram a estudar.

Ao convidá-los a frequentar esta disciplina, minha intenção é aproximá-los das questôes que preocupam os futuros professores de arte, possibilitar que se familiarizem com os princípios que norteiam a área e observar se, dessa forma, conseguem ir além da resposta padrão de que arte serve para desenvolver "criatividade e sensibilidade".

Como essas aulas aconteciam no segundo semestre, e estávamos no início do ano, havia um tempo para um trabalho preliminar. Ao invés de indicar uma bibliografia específica, sugeri que exercitasse seu olhar para a arte, visitando exposiçóes, assistindo a filmes e observando as aulas das "suas cruzes" no projeto em que trabalhava. Queria verificar o que a impressionava neste universo, sem um roteiro prévio.

Depois de um semestre observando, ela chegou para assistir as minhas aulas com mais interrogaçóes e nenhuma resposta. E, na nova turma, com os colegas do Instituto de Arte, repetiu o exercício de se perguntar: $\mathrm{O}$ que é arte para você? Como a arte entra na sua vida?

Depois dessa primeira aula, ofereci vários textos para os alunos, que deviam escolher um para trabalhar individualmente ou em dupla e, posteriormente, apresentarem para os colegas. Caroline escolheu um texto do artista catalão Antoni Tàpies, dizendo que já havia visto um vídeo sobre ele e fora surpreendida ao perceber muita 
semelhança entre suas pinturas e aquelas das crianças com quem trabalhava. Como assistira ao vídeo em catalão, sem legendas, o grande impacto foram mesmo as imagens. Foi o primeiro movimento, ainda que tímido, para o entendimento de que as pinturas podiam falar...

Quando percebi o quanto a pintura de Tàpies a havia impressionado, encontrei a primeira via de acesso para orientar o trabalho.

\section{Um tempo para as imagens}

Christian Gaillard (2004), no texto Jung and the arts, ajudoume a identificar alguns procedimentos que utilizo na orientação, enquanto método, que ainda não havia conseguido explicitar com a mesma clareza. Propóe que, diante de uma obra de arte, a atitude junguiana é fazer uma pausa, tão longa quanto for necessário, para emergir tudo que for preciso ser descoberto. Realmente, o termo apropriado é "deixar acontecer”. Ele diz que Jung tem uma palavra para descrever o primeiro estágio na análise de uma obra, o primeiro passo em seu método:

Ele usa o verbo duplo em alemão: "geschehen lassen" - em francês "laisser advenir", em inglês "to let happen". Deixar acontecer implica, também, deixar-se impressionar, permitindo que a obra se apresente diante de você e em você, dando espaço para isto e, então, abrindo sua percepção e consciência para que as impressões, sensações e sentimentos venham, gradualmente, à superfície ou que se imponham o mais emocionalmente possível. (Gaillard, 2004, p. 3)

O que procurei, através da orientação, foi que a aluna se permitisse dar o tempo necessário para olhar e perceber o que a impressionava, o que acontecia enquanto observava as imagens que se apresentavam diante de seus olhos; fossem estas pinturas de um artista ou de crianças. E, para isso, tivemos o tempo a nosso favor. Digo isso porque o tempo da academia é muito curto para o amadurecimento de um TCC. Nem sempre posso sugerir que o aluno detenha-se tanto tempo numa imagem. Mas, no caso desta aluna, por um problema de demanda de horário do projeto onde trabalhava, a orientação se estendeu por dois anos. Ela trancava a matrícula e voltava no semestre seguinte, dando tempo para o texto acontecer.

Como ela já havia assistido ao vídeo em catalão e identificado na obra de Tàpies a mesma gestualidade que encontrava nas pinturas das 
crianças que coordenava, apresentei-lhe o vídeo novamente, mas, desta vez, com legendas em português. Lendo as falas, ficou surpresa ao perceber que suas impressões se confirmavam e constatou que imagem e escrita podiam dizer coisas semelhantes. Sugeri, então, que copiasse todas as legendas e as estudasse em conjunto com o texto de Tàpies que já tinha em mãos.

Quando encontrou em Tàpies as cruzes, um símbolo recorrente em suas obras, as primeiras conexóes começaram a acontecer. $\mathrm{O}$ texto começava a ser escrito:

"A cruz é mais do que um sinal de morte no cristianismo. É desde um símbolo universal das coordenadas de espaço até como marcamos território, uma marca de destruição ou negação" ( Antoni Tàpies). A cruz sempre fez parte da minha vida, da minha educação cristã. Mas ela veio demarcar um outro momento, intrinsecamente relacionado à minha relação com a arte. Um momento onde conceitos e preconceitos começaram a ser destruídos, negados, desfeitos, desordenados, ao mesmo tempo em que marcava um novo momento de me relacionar, estar, perceber e olhar o mundo. Já havia ouvido dizer que imagens são textos, que podem falar sobre o que nos cerca, sobre nós mesmos, sobre possibilidades, sobre sentimentos, mas agora isso passava a fazer parte da minha vida de maneira consciente e coerente, de meu repertório cultural. E nasceu na forma de um incômodo. Marcando um novo olhar. (Silva, 2003, p. 11)

Em seguida, ela descreve o encontro com suas cruzes:

(...) acabei acompanhando parte de um processo de atividades de Artes Visuais, onde as crianças começaram a pintar, desenvolvido por dois colegas. O Zé e o Poletto. Trabalhávamos juntos, convivíamos, conversávamos, discutíamos, mas eles passaram a ser "a minha cruz". Traziam-me um incômodo saudável. Começaram a demarcar um novo território para mim. A convivência com eles, com as crianças que participavam de suas atividades e com o modo como se relacionavam com as crianças me incomodava e me intrigava. Sempre repeti o discurso de que a possibilidade de participar de atividades artísticas era muito importante para as crianças, isso "fazia muito bem para o desenvolvimento delas". Mas repetia o que ouvia. Na verdade, não sabia por que. E, nesse momento, senti que não sabia mesmo. (Idem, ibid., p. 13)

O trabalho havia começado e, a partir daquele momento, definimos uma rotina: observar as crianças em atividade, anotar as observações num caderno de campo, registrar em fotos as situações que 
capturavam sua atenção. Nossas conversas, a partir de então, giravam em torno destes registros.

Paralelamente, eu continuava acompanhando o trabalho de Poletto com as crianças. Ele me trazia, regularmente, uma pilha de pinturas e comentávamos detidamente cada uma. Quando terminou a licenciatura, continuou indo a minha casa, levando trabalhos para discutirmos os processos de cada criança e percebia que tudo que estávamos descobrindo, o conhecimento que ele estava construindo, não estava chegando à coordenação do projeto. Não estavam conseguindo ver por que não tinham os instrumentos necessários para tanto.

Isso eu podia constatar, claramente, pelas observaçôes periódicas que Caroline me trazia. Ela ia ao ateliê, olhava, mas não via o que estava acontecendo. Eu insistia, pedindo que se deixasse impressionar pelo que as crianças produziam, que se permitisse adentrar naquele território desconhecido. Afinal, já havia sido impressionada pelas pinturas de Tàpies, que era um desconhecido também. Ela tinha uma visão muito pragmática do que devia ser um bom trabalho, o que a impedia de ver o que estava acontecendo no ateliê. E eu esperava pelo momento em que fosse capturada pela poesia que via fluir nas pinturas daquelas crianças.

Procurei prolongar este tempo de observação, evitando que recorresse, prematuramente, à bibliografia especializada e continuasse a repetir conceitos que, na verdade, ainda não faziam sentido para ela. Evidentemente, depois ela foi buscar suporte teórico para dialogar com o que havia descoberto. Mas, naquele momento, queria ver se as imagens falavam com ela, se podia aprender algo com as imagens. Esperava pela experiência estética que as vozes-pinturas daquelas crianças seriam capazes de provocar. Depois de um tempo neste exercício, finalmente, a bruma começou a se dissipar e ela pôde enxergar o que acontecia naquele espaço.

Num dia que poderia ter sido como os outros, Caroline estava circulando pelo ateliê, observando. Foi quando reparou em Eliane pintando:

(...) Ia andando e parando para observar algumas crianças, mas um tanto quanto mecanicamente. Foi então que passei por ela. Pela Eliane, que pintava de costas para mim. Não deu para, logo de imediato, olhar para 
o que ela estava fazendo, porque ela estava entre o papel e eu, então dei alguns passos, olhando para frente e para outros que pintavam ali, mas acabei voltando minha cabeça para trás para mais uma olhadinha para Eliane. E aí olhei para o papel dela. Agora era possível enxergá-lo, ainda que meu corpo estivesse meio retorcido, já que estava voltado para outra direção. Eu ia continuar circulando. Mas parei.

Ela estava usando um pincel de mais ou menos $2 \mathrm{~cm}$ de largura e, com a tinta preta, traçava linhas grossas e circulares e as dispunha no espaço branco do papel, formando curvas como se fossem antenas de borboletas. Eram quatro imensas que preenchiam todo o papel. Nas pontas formavam caracóis. E meu corpo foi se colocando de frente para ela, fiquei curiosa na expectativa do que viria em seguida, tive até o ímpeto de perguntar, mas resolvi me calar e esperar. Observava a calma, a paciência e a graciosidade com as quais ela pincelava o papel. Ela deixou o papel por alguns minutos para se dedicar à tarefa de preparar as cores que usaria em seguida, partiu para a mistura de tintas que estavam em sua "fôrmapaleta". E que tarefa importante! Ela gastava muito tempo com cores primárias à sua disposição e ia escolhendo algumas, com o pincel já molhado na água e limpo da tinta preta anteriormente utilizada. (Silva, 2003, p. 40)

Todo esse movimento aconteceu sem que ela esperasse e o descreveu, minuciosamente, com detalhes que só são perceptíveis ao viajante que olha uma paisagem desconhecida pela primeira vez. E terminou com as seguintes observações:

Eu não sabia que olhar aquilo, as cores, os movimentos da Eliane e como tudo ia se organizando no papel, podia me transmitir sensações. E, conforme eu fui me dando conta disso, é que surgiu a vontade de chorar. Impactou-me o fato de me dar conta de que a pintura da Eliane, ou melhor, meu contato com a pintura da Eliane e observá-la pintando, fazia surgir sensaçôes. Então, conclui que a pintura estava conversando comigo e me fazendo conversar comigo mesma. (...) lembrei-me do incômodo do meu amigo, pensei nas experiências que tive nas aulas de Educação Corpo e Arte (...). Senti que realmente havia coisas intrigantes por trás dessa história de arte. Senti novamente as perguntas "Para que arte? Que importância ela tem?” crescerem dentro de mim e de repente achar uma "luz". Essa experiência me proporcionou encontrar uma das respostas às benditas perguntas que me perseguiam há tempos... Ela pintou mais dois parecidos com estes que relatei. Como uma série, e deu para mim. Sem que eu pedisse. (Idem, ibid., p. 42) 


\section{Territórios com fronteiras bem demarcadas}

Vivemos na escola a demarcação de territórios, a delimitação de áreas de conhecimento. E estou propondo aqui uma possibilidade de encontro. Mas um encontro que apenas pode ocorrer quando, cientes das especificidades de cada campo, os sujeitos se dispuserem a olhar, a procurar compreender as diferenças e, então, a iniciar um diálogo.

Se os pedagogos não entendem os artistas, poderíamos nos perguntar se estes se preocupam em se fazerem entender. Tive o privilégio de acompanhar o processo de ambos os lados.

Percebia como o Poletto entrava em conflito com as condiçóes de trabalho e como precisou aprender a negociar o tempo, o espaço e os materiais necessários para o tipo de atividade que queria realizar. Precisou aprender a linguagem adequada para se comunicar com os colegas das outras áreas e com cada criança, como organizar as atividades, como impor limites, como acolher as diferenças. Precisava da parceria com a coordenadora do projeto e isso demandou um longo aprendizado.

Após anos supervisionando estágios de ensino de arte, constato que a maioria dos professores encontra dificuldade em compreender o papel da coordenação pedagógica nos espaços educativos que compartilham (e vice versa!). Muitas vezes, são rebeldes, outras vezes submissos demais a programas e projetos externos e mal compreendem o campo de conhecimento em que estão trabalhando. Não conseguem justificar a especificidade da área de arte e, por isso, submetem-se às demandas normativas dos programas oficiais, reproduzindo, com raras exceçôes, atividades que não têm significado nem para eles, nem para os seus alunos.

Pela minha experiência anterior, trabalhando com crianças e adolescentes, assim como, atualmente, supervisionando estágios na Universidade, constato que professores que entendem, com clareza, qual é o seu objeto de trabalho e demarcam seu território podem, com mais possibilidade de sucesso, abrir as fronteiras e olhar para o campo vizinho. Isto é, abrir é dialogar com o outro, seja este a coordenação, os colegas de outras áreas ou os pais dos alunos; e, consequentemente, conseguir melhores condições de trabalho. 
A voz da pintura

Venho pesquisando, há alguns anos, histórias de iniciação na arte, observando, particularmente, como o desejo de criação torna-se obra. Tenho dedicado especial atenção às obras onde se dá a perceber uma mutação no padrão de criação, que entendi ser o momento em que se define a voz do artista (Albano, 2007), isto é, o momento em que o artista se apropria da forma de um modo bastante pessoal, que passa a caracterizá-lo e que chamei de "sua voz" em termos visuais.

O Poletto foi um aluno que se interessou muito por essa pesquisa e resolveu observar como isso acontecia com as crianças. Quando começou a trazer os trabalhos produzidos em suas aulas para observarmos juntos, pude perceber como ele ia dando espaço para a voz de cada criança aparecer, ao instrumentalizá-las nos projetos de pintura.

No momento em que Caroline começou a observar a oficina de pintura, não somente como coordenadora, mas, também, com olhar de pesquisadora, foi descobrindo como Poletto trabalhava com as crianças, auxiliando-as na procura da própria voz. O que, no início, parecia aos seus olhos apenas uma profusão de borrões estranhos, foi, aos poucos, revelando projetos individuais de pintura, com motivos diferenciados. Pôde, então, começar a responder a uma de suas primeiras perguntas: "Que voz é essa, se estão dando aula de pintura?".

Ela observou que Poletto deixava propositalmente alguns livros de histórias infantis, juvenis, livros mais adultos e, também, enciclopédias à disposição das crianças. E percebeu que esse acervo aumentava conforme a demanda. Havia, também, alguns livros de arte com boas reproduçôes, que não estavam ali para serem copiados, pois não era esta a proposta. Porém, na medida em que algum participante da oficina pintava algo, que começava a se repetir e se constituir um projeto a longo prazo, o professor tinha a oportunidade de mostrar alguma pintura que pudesse contribuir para a ampliação daquele trabalho; alguma imagem que permitisse àquele aluno identificar semelhanças, ampliar horizontes, possibilitando, talvez, a sensação de pertencimento a uma "família visual".

(...) às vezes, contava um pouco da historia do artista, mas o objetivo era que a criança pudesse se expressar, usar, descobrir e desenvolver a própria voz. Ah! A Voz nas conversas com o Poletto e em reuniões que participávamos juntos, fui começando a compreender o que ele estava querendo 
Arte e pedagogia: além dos territórios demarcados

dizer quando falava da voz. Nos objetivos de sua oficina, estava sempre lá: Descobrir a voz interior. (Silva, 2003, p. 32)

Caroline começou a reconhecer essa voz se diferenciando, quando observou o trabalho do Elias:

Não sei como o Elias começou a pintar daquele jeito, nem quando descobriu que podia fazer aquilo, mas na primeira vez que fui observar a oficina ele já estava completamente envolvido naquele projeto. E outros, inclusive, o acompanhavam. Ele, primeiramente, cortava um pedaço de papel da bobina, a maioria era de mais ou menos 70 por $70 \mathrm{~cm}$, pouquíssimos ficavam menores que isso. Dobrava ao meio e ia recortando de forma que os dois lados, ao abrir o papel, estivessem com o mesmo formato, em espelho. Depois, ele cortava um pedaço de papel um pouco maior, colocava "o molde" em cima e pintava sobre o molde, deixando a tinta, propositalmente, espalhar sobre o papel de baixo. A marca do molde ficava ali, lembrando um pouco a simetria das asas da borboleta. Ele pintava com rapidez e presteza. Foi como se ele tivesse imergido nesse jeito de pintar. E foi "sofisticando" as formas, as cores, fazendo coloridos com movimentos diferentes, com pincéis, papéis maiores, menores, por vezes não usando "o molde", mas a parte que sobrava do molde, num movimento contrário de preenchimento do papel de baixo. (Idem, ibid., p. 37)

Começava, assim, a enxergar a intenção que singulariza o modo de pintar de cada criança, "sua voz":

(...) fui capaz de começar a discernir as vozes deles. Embora o processo inicial fosse bem parecido em todos, guardadas as diferenças de tamanho de papel, tintas e cores, pincel e local escolhido para pintar, a partir desse momento cada um era um. Fui aprendendo a conhecer o timbre da voz diferente na produção de cada um (...) passei a saber quem tinha pintado o quê pela maneira como pintavam, e pelo quê pintavam(...). Esse outro jeito de falar. Essa outra e também mesma voz. Olhava e dizia: esse é do Elias, né? E esse da Eliane! E esse do Rodrigo. E essa é a série de transportes do Jefferson. Eles davam continuidade a algo que descobriam, eram provocados pelo Poletto a tentar ir mais fundo e não abandonar o descoberto. (p. 35)

\section{O caminho da imagem}

Hillman (1991), referindo-se às imagens oníricas, recomenda: “Detenham-se na imagem!". Ele acredita que devemos levar a sério as 
imagens que nos tocam, devemos ter com elas uma aproximação olfativa, reconhecê-las pelo cheiro, pois elas trazem consigo um apelo sutil, mas complexo, que pode nos conduzir a um conhecimento mais profundo das coisas e de nós mesmos. Creio que podemos aplicar o mesmo princípio às imagens pictóricas que nos impressionam.

"Imagens são daimones oferecendo indicações do destino", adverte Hillman, acrescentando, em outro momento: "Uma imagem particular é um anjo necessário, esperando por uma resposta. Como saudamos este anjo, depende da nossa sensibilidade para a realidade da sua presença" (1991, p. 50-51).

Deixando-nos guiar pela imagem inicial, das cruzes, que Caroline trouxera na primeira aula, amplificada pelas pinturas de Tàpies, encontramos o fio condutor que a levou, finalmente, à observação das crianças pintando e ao reconhecimento da singularidade que se manifestava em cada projeto. Pôde, então, começar a refletir sobre "essa tal de arte" e suas implicaçóes no projeto educacional que coordenava.

Orientando este trabalho, compreendi um modo junguiano de orientação, que corresponde à maneira como fui formada, como pesquiso e ensino. E com Christian Gaillard (2004) pude dar forma a este entendimento.

Jung usa o termo religião como relegere, como reler, observar atentamente, considerar, reconsiderar e pensar (Gaillard, 2004). E isso demanda tempo. Seria importante incluirmos esta forma de relegere na educação, dando o tempo necessário para a observação atenta na pesquisa, no trabalho cotidiano e nas relaçóes com o outro.

Em entrevista a Suzi Gablik (1997), Thomas Moore diz que, no Ocidente, perdemos a capacidade de contemplação, porque achamos que, enquanto contemplamos, não estamos realizando nada. $\mathrm{O}$ processo de criação, seja de criação intelectual, seja de criação artística, requer tempo, assim como observar a si mesmo, confrontar a si mesmo, observar as coisas, contemplar.

Venho refletindo sobre como a experiência com a arte pode proporcionar a experiência com o outro. O outro que está dentro de nós mesmos e o outro que está à nossa frente, manifesto em uma obra.

Penso que o trabalho de conclusão de curso proporcionou a Caroline esta forma de experiência, possibilitando que pudesse confrontar-se 
consigo mesma, reconsiderar posições e, finalmente, abrir-se para olhar o outro.

Tomei como objeto de reflexão neste artigo a relação entre uma pedagoga e um artista, como um pretexto, uma possibilidade de observar como a demarcação rígida de territórios pode impedir que duas pessoas, trabalhando juntas e dividindo responsabilidades, as compartilhem, sejam parceiras. Mas, principalmente, como uma oportunidade para refletir sobre a função da arte como experiência que pode abrir os sentidos e a percepção para o reconhecimento do(s) outro(s), quando há disponibilidade para deixar-se impressionar, dando tempo para emergir tudo o que for necessário ser descoberto. E, então, reconectarse com a relegere, relendo, observando atentamente, considerando, reconsiderando e pensando.

Comecei com as artes visuais e gostaria de terminar com o comentário de um músico, Du Moreira, sobre o trabalho em parceria:

Parcerias podem se dar de várias formas, mas a verdadeira comunhão só ocorre por meio da compaixão (...). Toda parceria artística deve ser fruto desse tipo de vivência. Nesse estado, estamos antes das escolhas. Toda nota que cada um toca é imediatamente sentida pelos outros, não como interferência externa, mas como presença sutil em suas próprias almas. Respostas vêm simplesmente como continuaçôes do movimento. Fazendo música da paixão pela compaixão, instrumentistas escutam mais do que tocam. (Moreira, 2003)

Fazendo educação da paixão pela compaixão, os educadores poderiam observar e escutar mais do que falar.

Recebido em julho de 2008 e aprovado em março de 2010.

\section{Referências}

ALBANO, A.A. Histórias de iniciação na arte. In: Ormezzano, G. (Org.). Educação estética: abordagens e perspectivas. Em Aberto, Brasília, DF, v. 1, n. 77, p. 85-95, 2007.

ALBANO MOREIRA, A.A. O espaço do desenho: a educação do educador. São Paulo: Loyola, 1984. 
GABLIK, S. Conversations before the end of time. New York: Thames and Hudson, 1997.

GAILLARD, C. Jung and the arts. Palestra apresentada no Seminário Internacional de Educação Estética, Faculdade de Educação da UNICAMP, abr. 2004. (não publicado).

HILLMAN, J. A blue fire. New York: Harper, 1991.

MOREIRA, D. Mani Padme. 2003. Disponível em: $<$ www.dumoreira.com>.

SILVA, C.C. Aprendendo a ver, alfabetizando o olhar. 2003. Trabalho de Conclusão de Curso (Pedagogia) - Faculdade de Educação, Universidade Estadual de Campinas, Campinas. 